\title{
PRIMARY LYMPHOSARCOMA OF THE LUNG
}

\author{
BY \\ C. W. H. HAVARD, J. B. NICHOLS, AND A. G. STANSFELD \\ From the Departments of Medicine and Pathology, St. Bartholomew's Hospital, London
}

(RECEIVED FOR PUBLICATION NOVEMBER 28, 1961)

Pulmonary involvement in disseminated lymphosarcoma is comparatively common. Vieta and Craver (1941) found an incidence of nearly $25 \%$ by radiographic assessment in a series of 239 patients with lymphosarcoma* and a similar proportion of a smaller number coming to necropsy. This figure agrees closely with the post-mortem incidence reported by Robbins (1953) in an even larger series. More recently, Rosenberg, Diamond, Jaslowitz, and Craver (1961) found approximately $40 \%$ with lung involvement in a necropsy series of 277 cases of lymphosarcoma. At St. Bartholomew's Hospital, 86 patients with histologically proven lymphosarcoma $\dagger$ have been admitted over the last ten years. In 12 of these patients there was radiographic evidence of pulmonary involvement.

Primary lymphosarcoma of the lung is, on the other hand, a rare disease. Sugarbaker and Craver (1940) found only one instance of a primary lung tumour in a series of 196 cases of histologically proven lymphosarcoma. Its importance, however, far outweighs the incidence, for it is a slowly growing tumour which tends to remain localized for a long time, spreading by direct extension into neighbouring structures, rather than metastasizing by the blood or lymph streams. The tumour is therefore often amenable to complete surgical excision.

The diagnosis of this disease is difficult, for symptoms are usually mild or absent and physical examination will at the most reveal signs of consolidation. The radiographic picture is nonspecific and in most instances has given rise to a suspicion of bronchial carcinoma. Baron and Whitehouse (1961) have, however, emphasized the patency of the bronchi in pulmonary lymphosarcoma and have drawn attention to radiographic appearances which they describe as an "air bronchogram.' Bronchoscopy has seldom proved helpful in diagnosis in spite of the frequent

\footnotetext{
* The term is used in the general sense by these authors to include all types of " malignant lymphoma."

$\dagger$ The term is here used in the restricted sense to mean a tumour of lymphoid cells.
}

infiltration of bronchial walls by the tumour. Cytological examination of the sputum has on at least one occasion led to a pre-operative diagnosis (Jackson, Bertoli, and Ackerman, 1951), but usually thoracotomy and lung biopsy are necessary to establish the diagnosis.

Reports of about 50 cases of primary lymphosarcoma of the lung have been published, although in some of these the widespread dissemination of the disease makes the pulmonary origin uncertain. Recent reviews have appeared in the American literature (Cooley, McDonald and Clagett, 1956 ; Rose, 1957 ; Sternberg, Sidransky, and Ochsner, 1959 ; Baron and Whitehouse, 1961) and subsequent cases have been reported by Prichard and Bradshaw (1961). Although Willis (1960) briefly mentions a case of pulmonary lymphosarcoma, no detailed report of these tumours has appeared in the British literature. For this reason our account of the clinical and pathological features of three further cases of primary lymphosarcoma of the lung is presented.

\section{Case Reports}

CASE 1.-J.H. is an engineer aged 48 years. In April, 1954, he developed pleurisy and a radiograph two months later revealed an area of consolidation in the right lower lobe (Fig. 1). He was admitted to hospital in November, 1954. At this time he did not complain of any symptoms although he admitted losing $11 \mathrm{lb}$. $(5 \mathrm{~kg}$.) in weight over the previous year. There were no physical signs of disease apart from a small mobile mass in the right axilla which was attached to the skin but not to deeper structures. It had been present for six years, according to the patient, and was considered to be a sebaceous cyst. The haemoglobin was $15.7 \mathrm{~g}$. per $100 \mathrm{ml}$. Leucocytes numbered 8,400 per c.mm., of which $73 \%$ were neutrophils, $24 \%$ lymphocytes, and $3 \%$ monocytes. The E.S.R. was $6 \mathrm{~mm}$./hr. (Westergren). Examination of the sputum failed to show acid-fast bacilli or evidence of fungal infection. Bronchoscopy was normal.

In view of the fact that the patient had been taking oily nasal drops for many years on account of nasal catarrh, a diagnosis of lipoid pneumonia was 


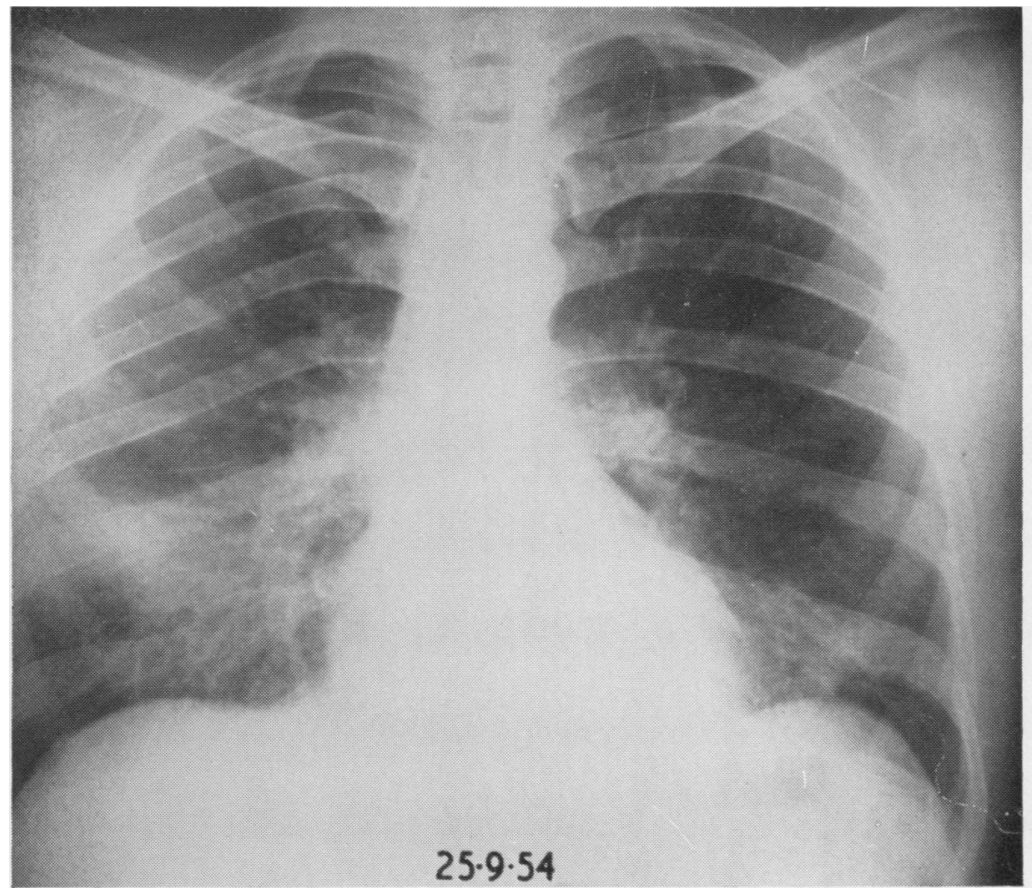

FIG. 1. Case 1. Chest radiograph in September, 1954.

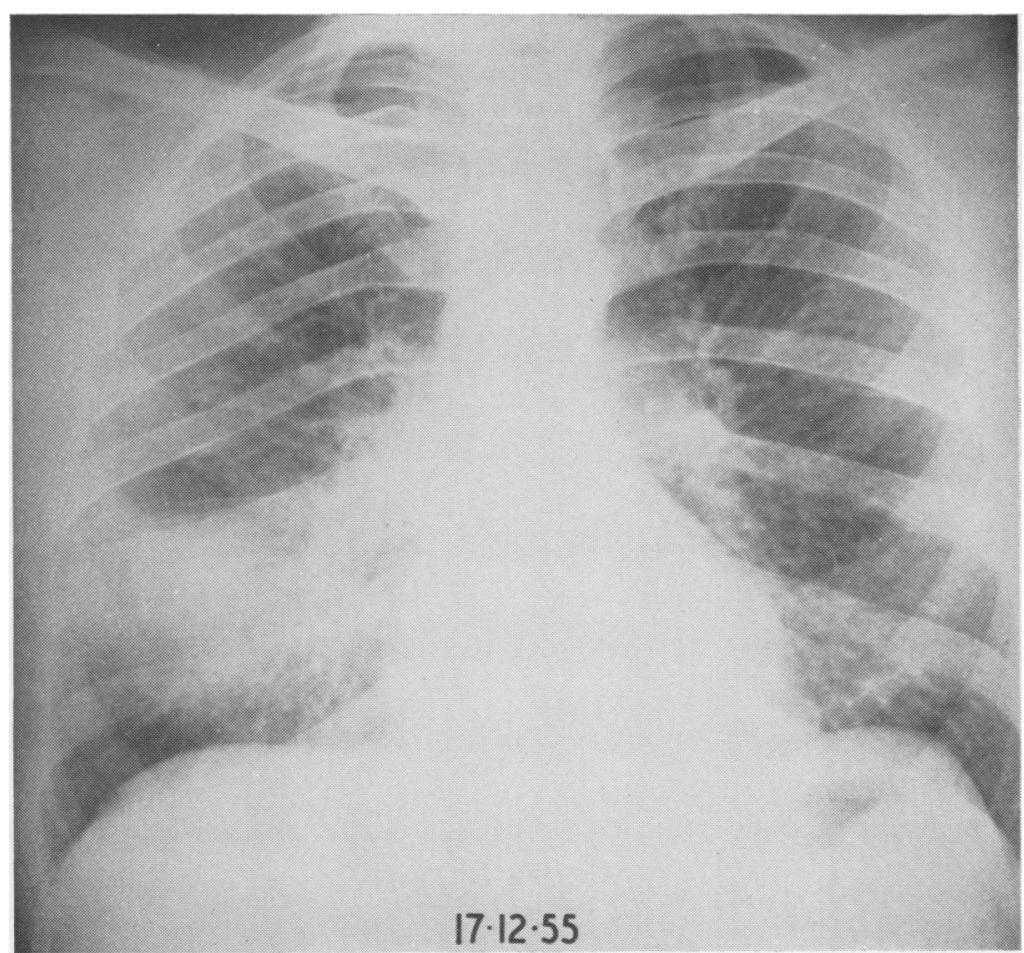

FIG. 2. Case 1. Chest radiograph in December, 1955. 


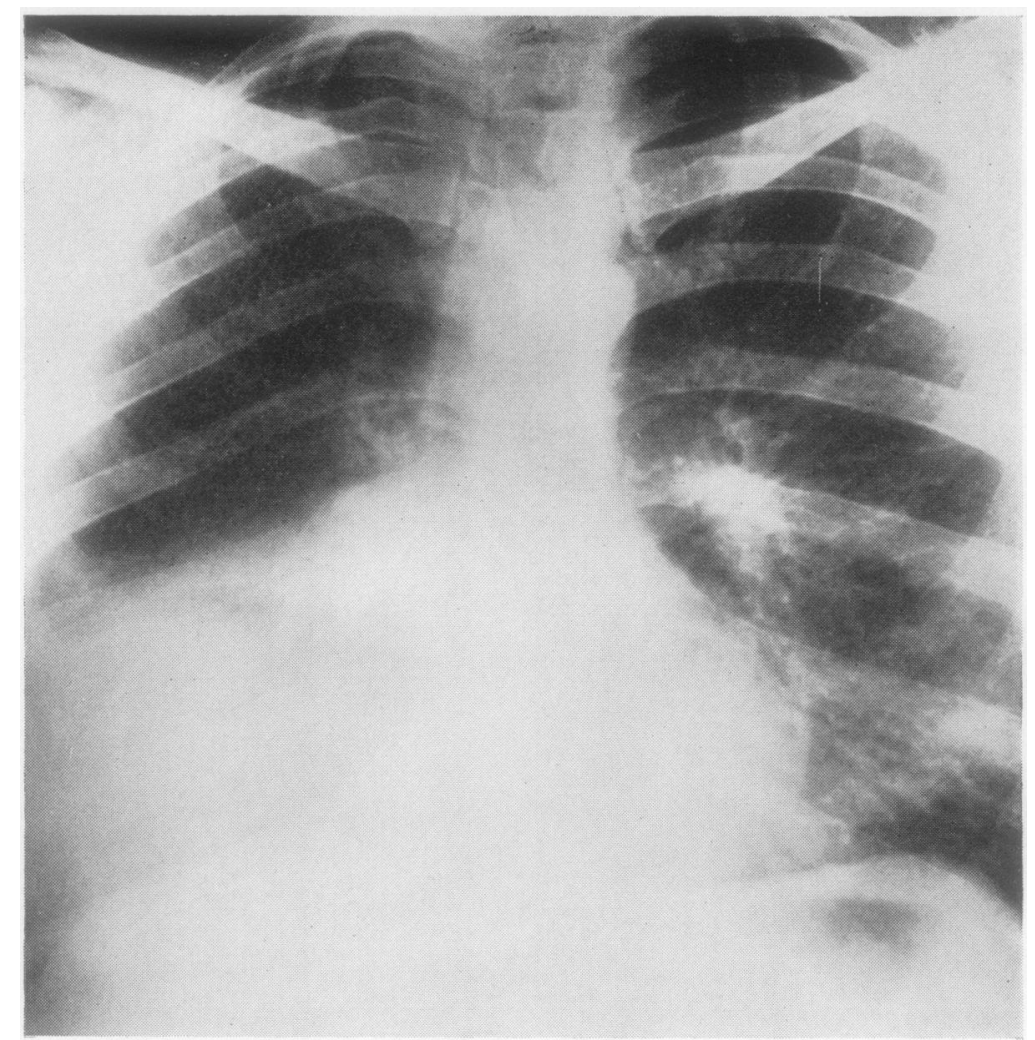

pIG. 3. Case 1. Chest radiograph in June, 1958.

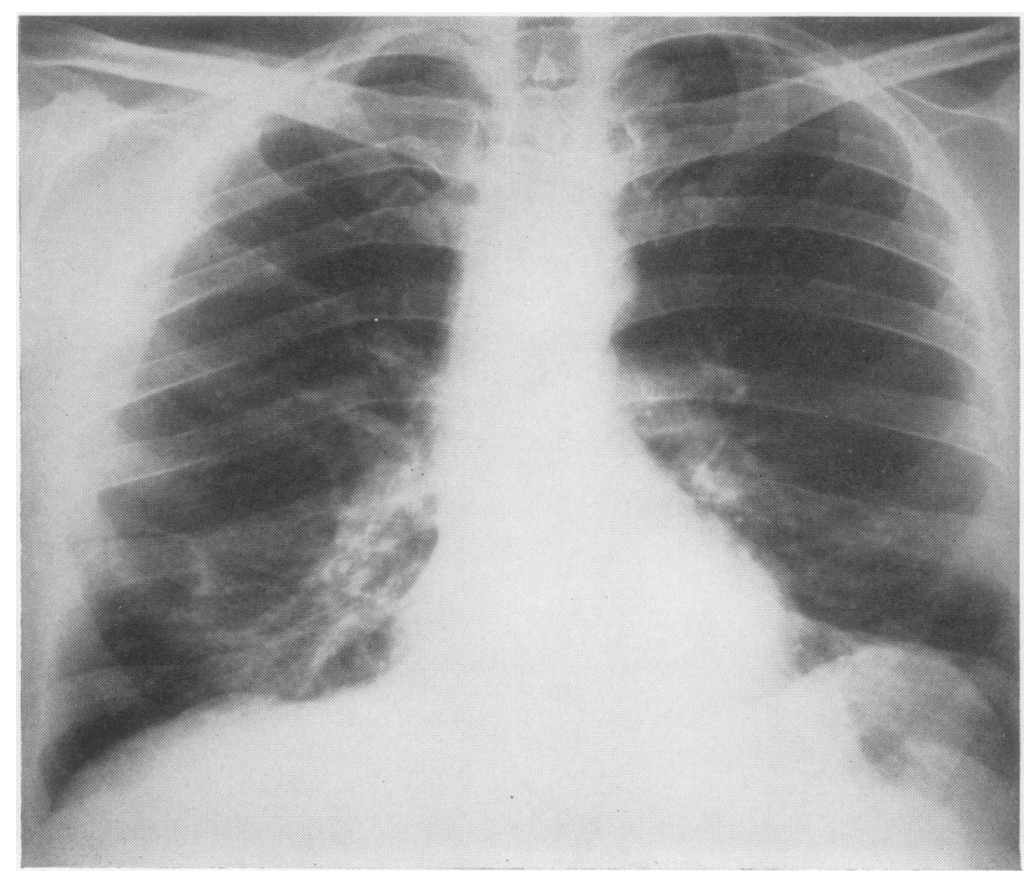

FIG. 4. Case 1. Chest radiograph in July, 1961. 

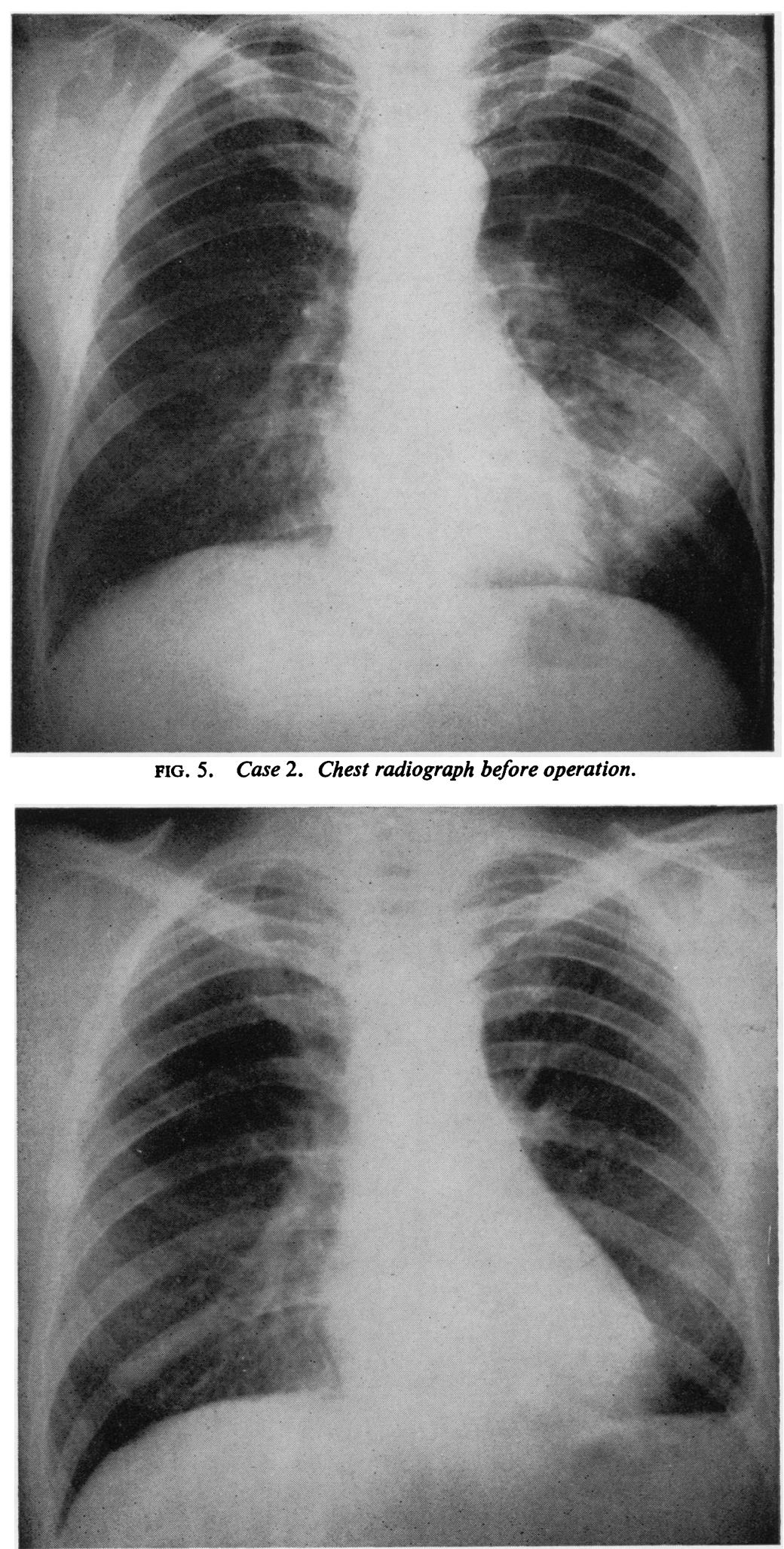

FIG. 6. Case 2. Chest radiograph one year after operation. 
considered likely. He was advised to discontinue the nasal drops and was kept under observation. Over the next three years he remained well but lost a further $11 \mathrm{lb}$. $(5 \mathrm{~kg}$.) in weight. The percussion note over the right lower zone became impaired and numerous fine crepitations persisted over this area. The cyst-like mass in the right axilla appeared to be a little larger. Serial radiographs showed a progressive increase in the size of the opacity (Figs. 2 and 3). A lung biopsy was obtained at limited thoracotomy in June, 1958. At the same time the small soft mass in the right axilla was removed. Operation confirmed that it was attached to the skin but not to deeper structures. The parietal pleura was opened by a small incision through the fourth intercostal space and appeared normal. The right upper lobe looked normal, but the middle and lower lobes were firm in consistency and had an opaque greyishpink colour. Histological examination of the axillary tumour showed infiltration of both skin and subcutaneous tissue by lymphosarcoma and a similar type of growth was seen in the lung biopsy. Small numbers of fat- and lipoid-containing phagocytes were also present.

The patient was treated with deep $x$ rays in the form of a thoracic bath including the axilla: $600 \mathrm{r}$. was given through four oblique fields. There was a dramatic response; the lung crepitations disappeared and the patient gained $22 \mathrm{lb}$. $(10 \mathrm{~kg}$.) over the subsequent 12 months. The radiological changes regressed and the improvement has been maintained for three years (Fig. 4). In March, 1961, a few slightly enlarged lymph nodes appeared in the left supraclavicular region; the patient was otherwise well and the nodes have not increased in size over the subsequent six months. No further treatment has been given and the blood count remains normal.

CASE 2.-F. B. is an insurance clerk aged 36 years. In July, 1960, a mass miniature chest radiograph revealed an ill-defined area of consolidation in the lingula of the left upper lobe. He had no symptoms and his general health was good. There were no physical signs of disease and the erythrocyte sedimentation rate and the blood count were normal. The bronchial tree was normal on bronchoscopy and bronchography and he was considered to have a resolving pneumonia. In October, 1960, he had a small haemoptysis and continued to expectorate a little dark altered blood over a period of four days. On physical examination a few crepitations were audible over the left mid-zone and radiography showed an increase in the area of consolidation in the lingula (Fig. 5). The haemoglobin was $12.8 \mathrm{~g}$. per $100 \mathrm{ml}$. and the leucocytes numbered 8,000 per c.mm. (neutrophils $66 \%$, lymphocytes $32 \%$, monocytes $2 \%$ ). Acid-fast bacilli were not found in the sputum. Thoracotomy was performed and a uniform, well-demarcated area of consolidation was found, involving the lingula and a small part of the anterior segment. The bronchi were not compressed, the mediastinal nodes appeared normal, and there was no pleural effusion. The abnormal segments of lung were resected. Microscopy showed a well-differentiated lymphosarcoma of the lung.

The patient has remained well since operation and a chest radiograph 12 months later showed no evidence of recurrence (Fig. 6).

CASE 3.-R. O. is an engineer aged 42 years. A mass miniature chest film in January, 1957, showed an opacity in the right middle lobe (Fig. 7a and b). The patient had no symptoms and there were no physical signs of disease. The blood count and erythrocyte sedimentation rate were normal and no abnormality was detected on bronchoscopy. He was kept under observation and little radiological change was apparent over the subsequent 12 months. A further bronchoscopy showed that the right middle lobe bronchus was pulled down at its origin but no other abnormality was detected. The haemoglobin was $14.1 \mathrm{~g}$. per $100 \mathrm{ml}$. and the leucocytes numbered 3,500 per c.mm., of which $66 \%$ were neutrophils and $34 \%$ lymphocytes. The E.S.R. was $4 \mathrm{~mm}$. $/ \mathrm{hr}$. (Westergren). At thoracotomy in January, 1958, a firm mass of grey consolidation $4 \mathrm{~cm}$. in diameter was found in the periphery of the middle lobe, extending across the lesser fissure into the anterior segment of the lower lobe. A right middle lobectomy and anterior segmental resection was performed and the patient made an uneventful recovery. Microscopy showed a well differentiated lymphosarcoma of the lung. He has remained well and without symptoms over the following two and a half years and a chest radiograph in July, 1961, showed no evidence of recurrence (Fig. 8).

\section{Pathology}

The findings in the biopsy specimen of case 1 and the resection specimens of cases 2 and 3 are so similar that they will be described together.

Macroscopically the affected lung presents a firm, pinkish-grey consolidation, which resembles pneumonic consolidation in that the lung markings are still preserved on the cut surface of the tumour. The edge of the tumour is often indefinite.

On histological examination the lung tumour is composed of closely packed masses of rather uniform small lymphocytes showing scanty mitotic figures. A striking feature is the manner of spread through the lung, which is almost entirely interstitial. This can be clearly seen towards the periphery of the growth where there is obvious thickening of alveolar walls due to lymphocytic infiltration (Fig. 9). At intervals the interalveolar septa are expanded by nodular foci of similar cells, which are often seen to surround small arterioles along which the growth appears to be spreading (Figs. 9 and 10). Towards the centre of the tumour these nodular foci become larger and more numerous until they are coalescent, but even in apparently 


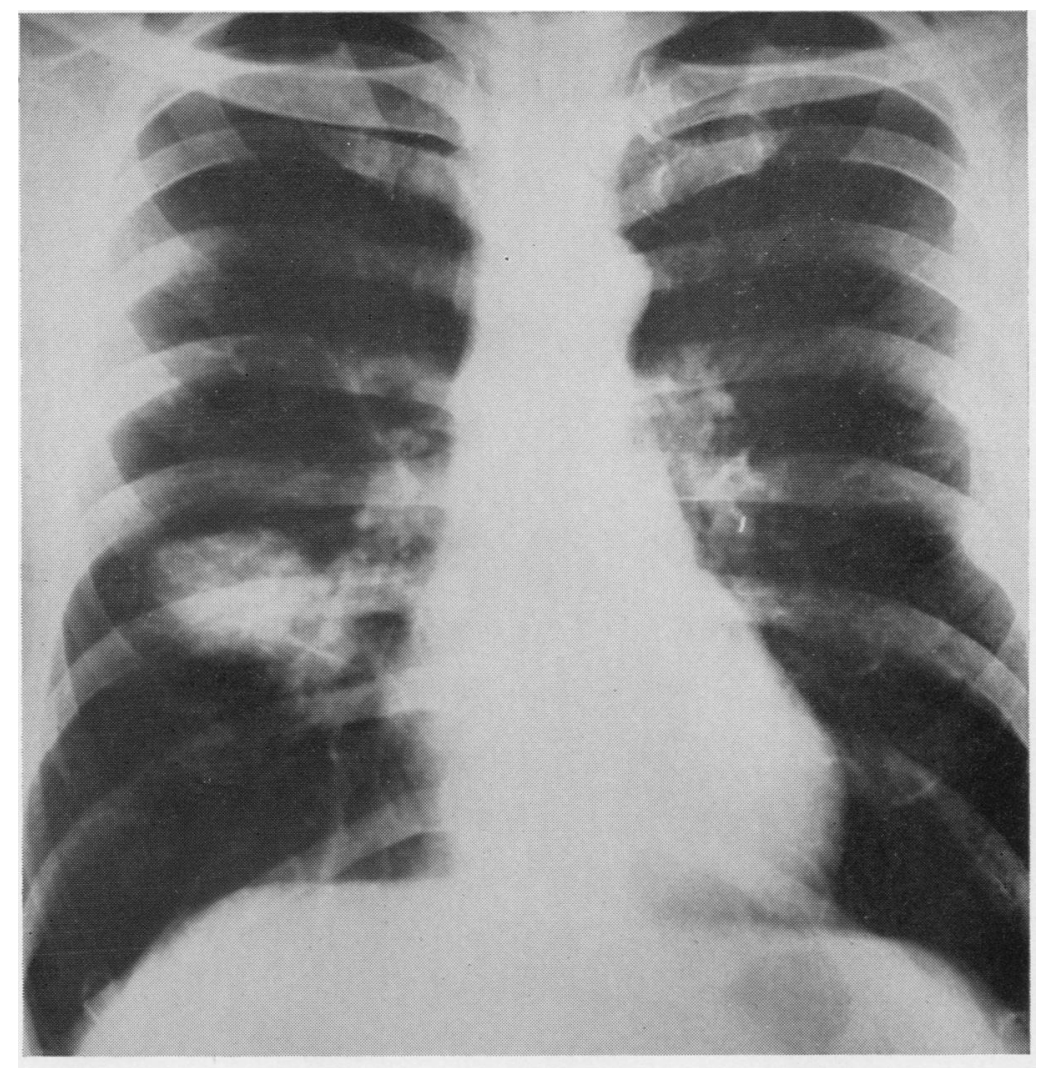

FIG. 7. Case 3: (above) Postero-anterior and (below) lateral chest radiographs before operation. 


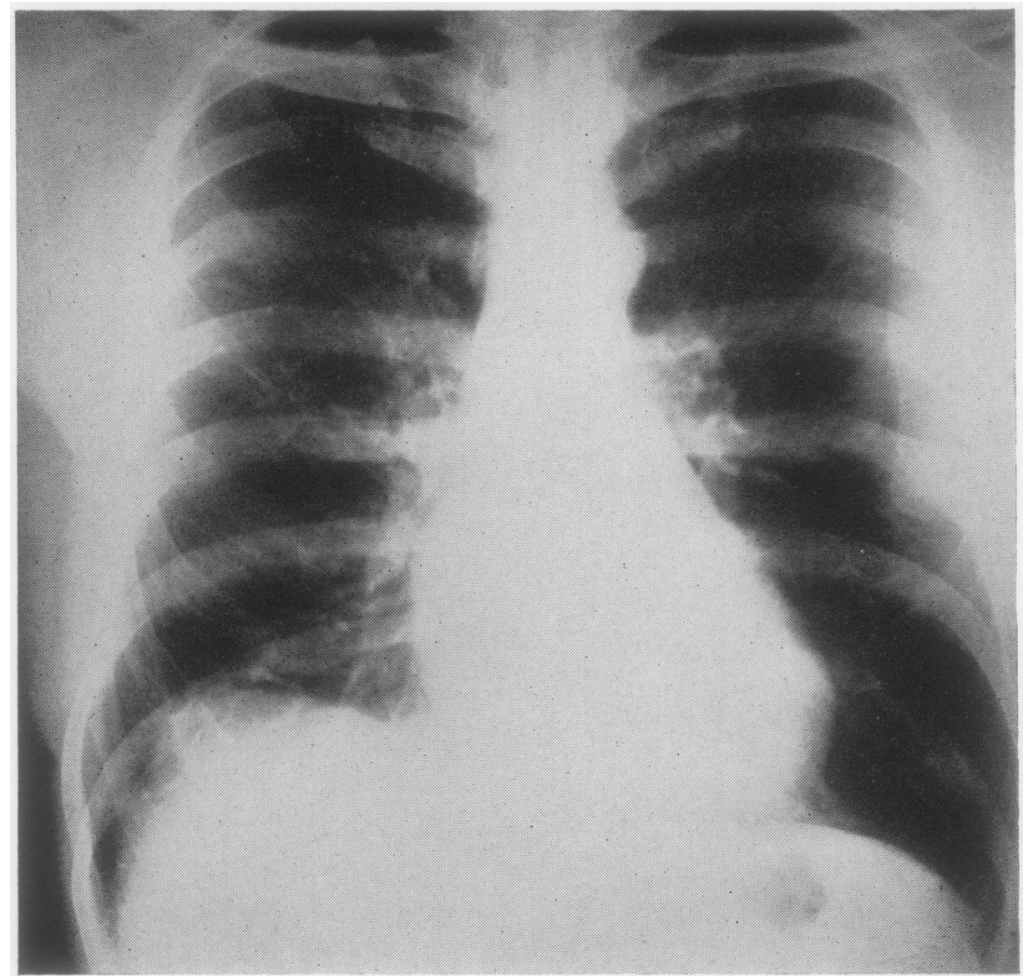

FIG. 8. Case 3. Chest radiograph two and a half years after operation.

solid parts of the mass compressed alveoli and clefts lined by columnar epithelium may still be seen (Figs. 11 and 12). The discrete tumour nodules projecting into alveoli are often capped by a syncytium of proliferated alveolar epithelium, as can be seen sometimes with carcinomas in the lung (Fig. 13). There is little tendency for the tumour to invade the air spaces of the lung, although some bronchioles and alveoli contain free lymphocytes, together with foamy macrophages and occasional cholesterol crystals.

The walls of bronchi are infiltrated by masses of lymphoid cells which fill the submucosa and encroach upon the lumen, but there is seldom destruction of the epithelial lining (Fig. 14). In case 1 some of the compressed bronchioles are partly or wholly filled with metaplastic squamous epithelium (Fig. 15). Except for some minute venules, the walls of blood vessels are not infiltrated by growth. The sections of cases 1 and 2 show characteristic neoplastic infiltration of the pleura.

The pattern of the lung tumour in each of these cases is that of a diffuse lymphocytic lymphosarcoma. Although the focal lymphocytic aggregates at the periphery have the appearance at first sight of lymph follicles, the more central parts of the growth have lost all semblance of a follicular pattern and we have been unable to establish the existence of true follicles. The tumour in the axillary skin and subcutaneous tissue of case 1 also shows a diffuse lymphosarcomatous growth with no hint of a follicular pattern (Fig. 16). The amount of reticulin in silver impregnation preparations is variable, being scanty in cases 1 and 3 and relatively abundant in case 2 (Fig. 12), but in all three cases occasional coarse strands of hyaline collagen are seen.

\section{Discussion}

Although all our patients were male, in the 50 or so recorded cases of primary lymphosarcoma of the lung the sexes were almost equally affected. The patients' ages varied from 34 to 75 with a mean of 53 years. There were no symptoms in 15 patients but 19 admitted to a cough, which was complicated by haemoptysis in six instances. In eight patients there was a history of weight loss. It may be noted that atelectasis and infection are less common than they are with bronchial 


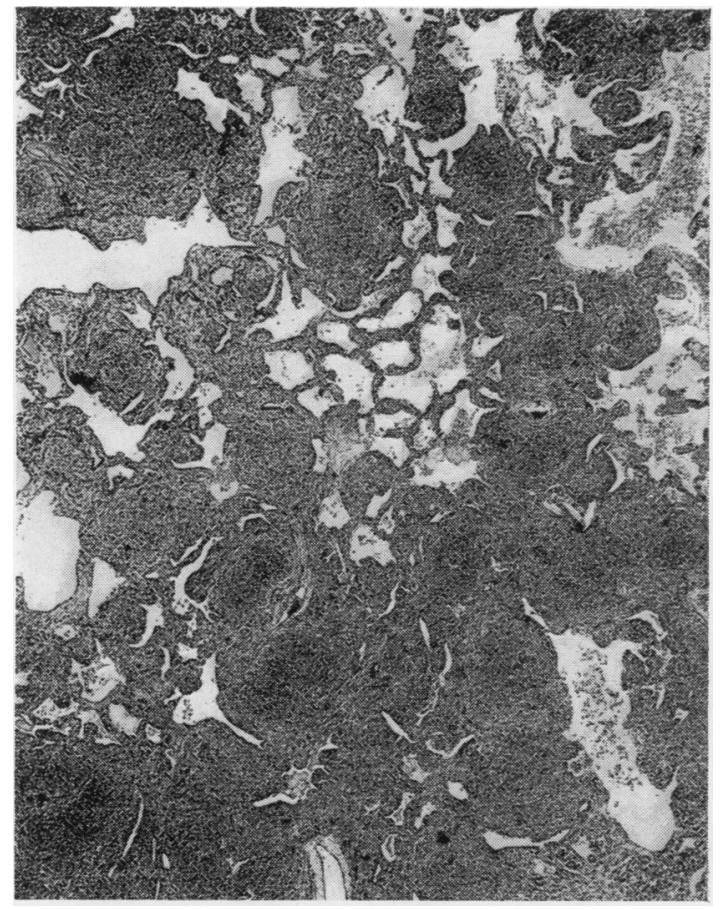

FIG. 9. Case 1. Low-power view showing interstitial spread and spurious follicular pattern (haematoxylin and eosin $\times 18$ ).

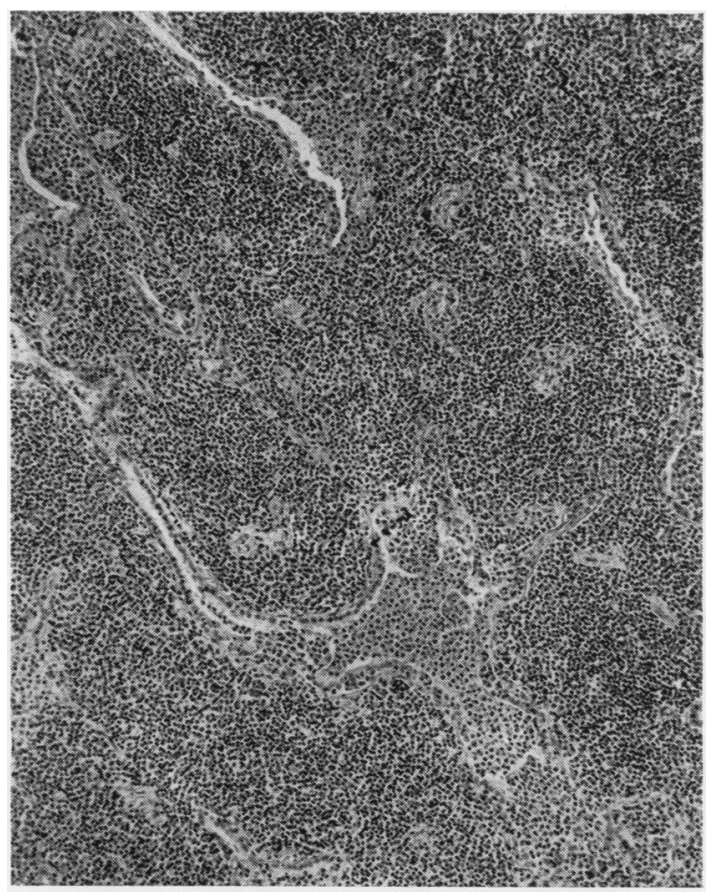

FIG. 11. Case 2. Central part of tumour showing preservation of epithelial-lined spaces (haematoxylin and eosin $\times$ 65).

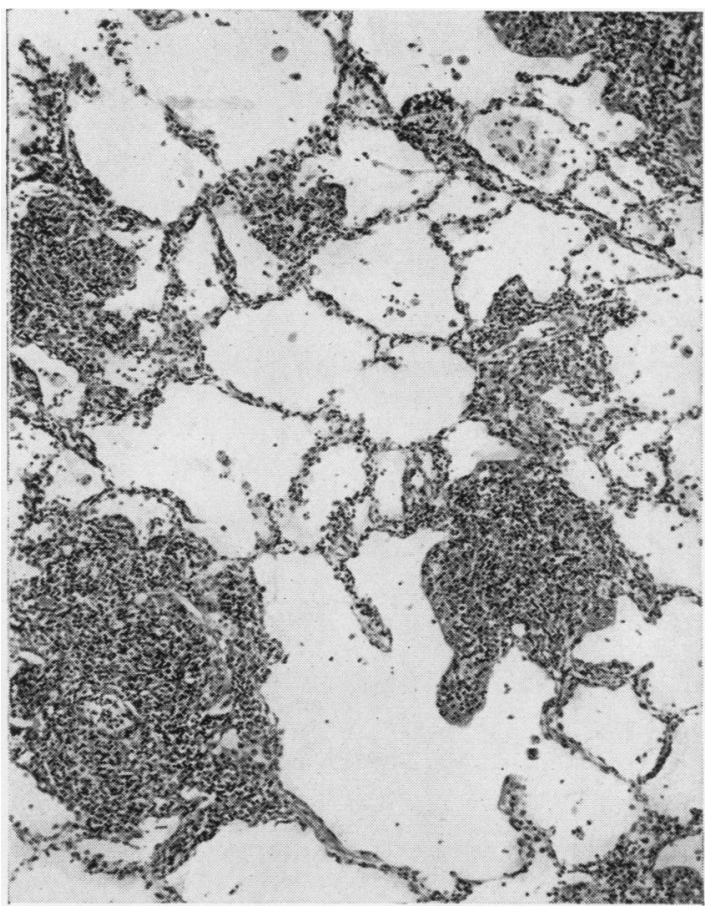

FIG. 10. Case 3. Nodular foci in the interstitial tissue of the lung at the periphery of the tumour (haematoxylin and eosin $\times 60$ ).

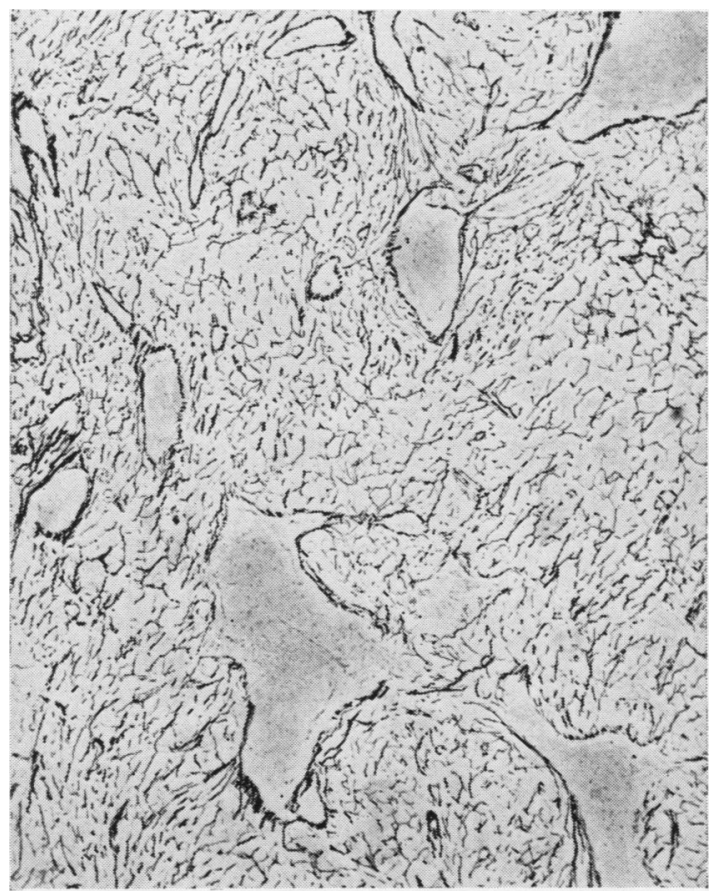

FIG. 12. Case 2. Similar field to that in Fig. 11, showing abundant reticulin in the tumour. The residual air spaces are sharply outlined (silver impregnation $\times 65$ ). 


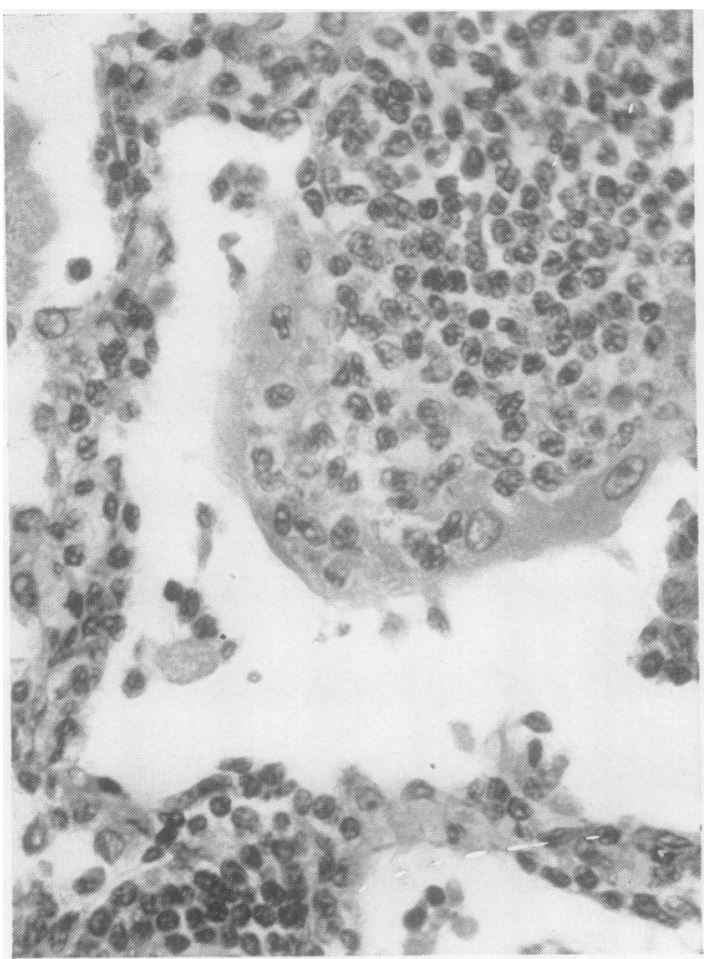

FIG. 13. Case 3. Syncytial cap of epithelium covering an intra-alveolar projection of tumour. Note lipoid-containing macrophages (haematoxylin and eosin $\times 400$ ).

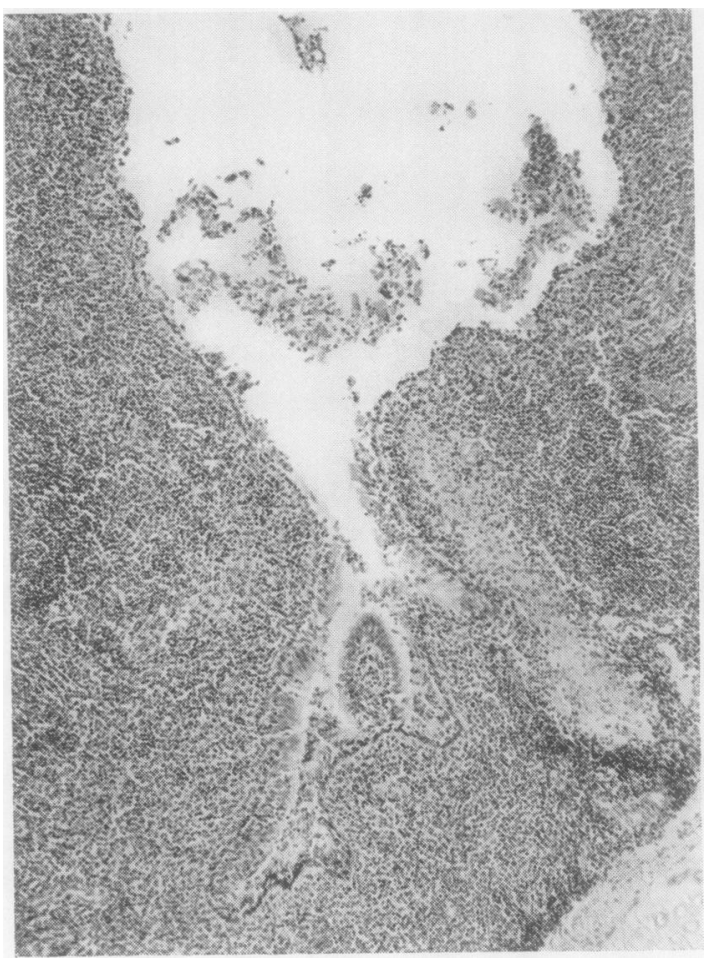

FIG. 14. Case 2. Lymphosarcoma infiltrating the wall of a bronchus. The epithelial desquamation is an artefact (haematoxylin and eosin $\times 65$ ).

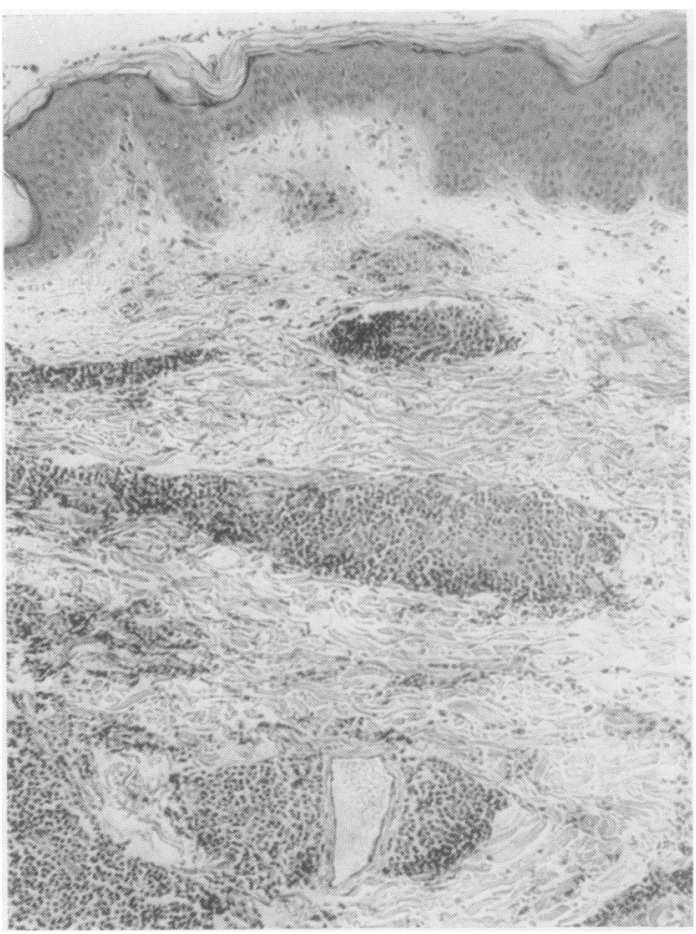

FIG. 16
Fig. 15

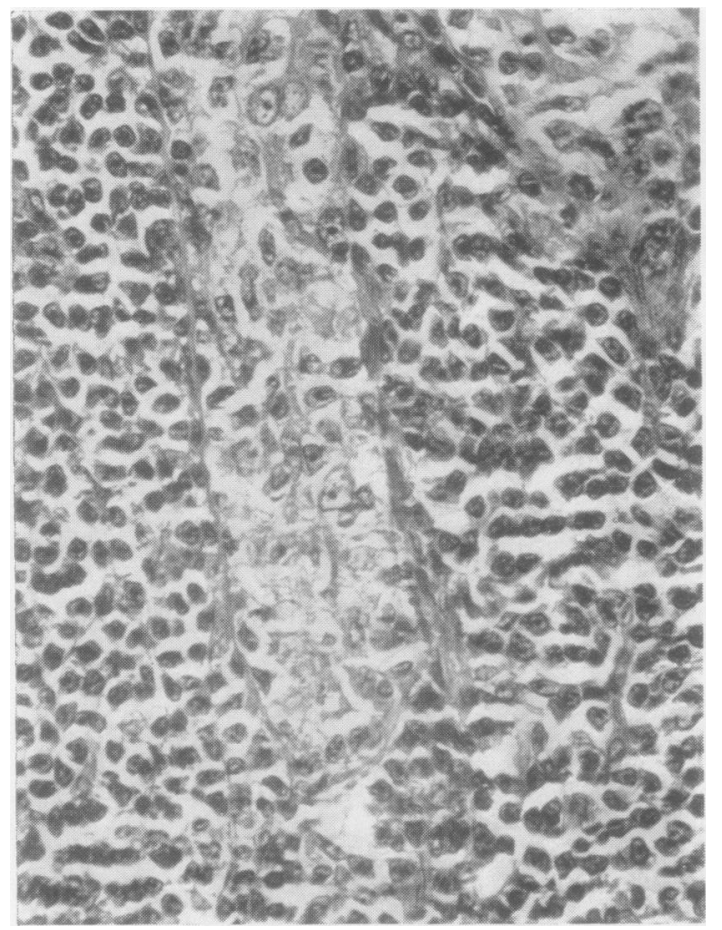

FIG. 15. Case 1. Squamous metaplasia in a bronchio'e surrounded by tumour (haematoxylin and cosin $\times$ 400).

FIG. 16. Case 1. Margin of axillary tumour showing lymphosarcoma infiltrating the skin and subcutis (haematoxylin and eosin $\times 85)$. 
carcinoma. The blood count and erythrocyte sedimentation rate were normal in our patients.

The initial treatment was by surgery alone in 28 patients, and surgery followed by immediate radiotherapy in 16 patients. Four patients received radiotherapy alone.

Of the 28 patients who received surgical treatment alone, nine were known to be alive and well five years later, although in two recurrence of lymphosarcoma had required treatment with radiotherapy. Of the 19 patients who had been followed up for less than five years, 11 were reported alive and well, having survived for periods varying between three months and three years after operation. Eight patients are known to have died, but at least three of these died from unrelated causes.

Of the 16 patients who received surgery and post-operative radiotherapy, four were alive and without evidence of recurrence five years later and one other was alive and well seven years after lobectomy, having had a hilar recurrence treated by radiotherapy. The 11 patients who had been followed up for less than five years had survived for periods of one to four years after operation. Two patients had died, six and 21 months after surgery.

Four patients received radiotherapy alone as their disease was inoperable. Two died within 14 months of treatment, one (our case 1) is alive and well seven and a half years after the onset, and another ten years after the onset of the disease.

It is difficult to compare the prognosis of primary pulmonary lymphosarcoma with that of lymphosarcoma elsewhere for two reasons. First the follow-up data on most of the reported cases of pulmonary lymphosarcoma are inadequate, and secondly the widespread dissemination of the disease makes the pulmonary origin of some cases uncertain. Nevertheless ten patients with primary pulmonary lymphosarcoma have been observed for periods of seven or more years. In four of these there was no evidence of recurrence, one of them surviving 14 years after operation and dying from an unrelated cause. In five patients the disease recurred, but certain survival periods of $7 \frac{1}{2}, 8 \frac{1}{2}, 10,12$, and $13 \frac{1}{2}$ years were recorded.

It seems clear from these figures that primary lymphosarcoma of the lung carries a better prognosis than lymphosarcoma in general. Not only has long survival after treatment been recorded, but in several patients there was radiographic evidence that the tumour had been present for a year or more before any treatment was instituted. In our first case this period was four years and in another reported case it was as long as five years.

There are possibly two factors that determine the relatively benign behaviour of primary lymphosarcoma of the lung, namely a slow rate of growth and a tendency to spread locally rather than metastasize. The seemingly uncharacteristic behaviour may raise doubts about the neoplastic nature of this condition, but histological examination of the lung tumours will dispel such doubts, for the appearances are unquestionably those of an infiltrating neoplasm, which is in most respects indistinguishable from lymphosarcoma occurring elsewhere. There is no histological resemblance to any form of pulmonary granuloma and the growth of the tumour is progressive though slow. Furthermore, it is well known that primary lymphosarcomas of some other viscera often display a similar type of behaviour (Shimkin, Oppermann, Low-Beer and Mettier, 1954 ; Harrison, 1960).

The slow rate of growth of primary pulmonary lymphosarcoma may in part be related to the degree of differentiation of these tumours, for the majority are of lymphocytic type with a strikingly uniform cytology. There is, however, some evidence that even reticulum cell sarcomas which are primary in the lung show a better prognosis than corresponding types of growth which arise in the mediastinal or other lymph nodes (Sternberg et al., 1959). It is doubtful whether the same applies to pulmonary Hodgkin's disease, but probably few, if any, of these tumours are really primary in the lung.

A remarkable feature of the reported cases of primary lymphosarcoma of the lung is the lack of mediastinal lymph node involvement. This has been noted so often, even in patients who have been under observation for long periods before operation, that the finding of extensive mediastinal lymph node involvement at thoracotomy would appear to throw doubt upon the diagnosis of primary pulmonary lymphosarcoma. The mediastinal lymph nodes may be found enlarged, but histological examination generally shows nonspecific reactive changes only. A long delay before the regional lymph nodes are affected has also been noted many times with primary lymphosarcoma of the gastrointestinal tract (Gall, 1943 ; Azzopardi and Menzies, 1960). The reasons for the failure to spread in pulmonary as in other visceral lymphosarcomas are obscure. It cannot easily be attributed to a lack of infiltrative capacity, since local spread in the lung is often extensive with pleural invasion and transgression of interlobar fissures. 
Sternberg et al. (1959) found a follicular pattern in some parts of each of the four lymphocytic lymphomas of the lung which they reported. We were unable to find true follicles in our three patients. The rounded, nodular masses of lymphocytes produced an appearance suggestive of lymph follicles, but in our view this pattern is a consequence of the interstitial manner of spread in the lung. This type of spread is not peculiar to primary lymphosarcoma of the lung, for we have found it also in secondary lymphosarcomas and reticulum cell sarcomas of the lung. Secondary lymphomas, however, show a much greater tendency to destroy the lung parenchyma and invade the walls of blood vessels and the lumina of bronchi. The relatively abundant production of reticulin in case 2 and the finding of strands of collagen in all three tumours are probably a reflection of the slow rate of growth, as seems to be the case with lymphosarcoma in other sites.

Antecedent factors in primary lymphosarcoma of the lung are unknown and the use of oily nasal drops by our first patient is probably of no significance, but it is of interest that Hall and Blades' (1959) second patient gave a similar history and was thought to have a patch of lipoid pneumonia in the lung opposite to that in which the lymphosarcoma arose. To our knowledge there is no recorded evidence to suggest that lymphosarcoma of the lung has ever developed secondarily to lipoid pneumonia. One of the patients of Sternberg et al. (1959) with a lymphocytic lymphoma of the lung had a history of recurrent respiratory infections and 18 months after lung resection the patient developed symptoms characteristic of Sjøgren's syndrome. The concurrence of these two uncommon conditions is interesting in view of the heavy lymphocytic infiltration characteristically found in the salivary and other upper respiratory glands in Sjøgren's syndrome, but these authors make no comment about a possible association between them.

\section{Summary and Conclusions}

The clinical and pathological details of three cases of primary lymphosarcoma of the lung are reported. Though an uncommon tumour, primary lymphosarcoma of the lung is a definite clinical entity. The tumour tends to remain localized for a long time and is thus often amenable to complete surgical excision. The diagnosis has rarely been made before histological examination of the tumour. It is usually a well-differentiated, lymphocytic lymphosarcoma, which spreads interstitially with relatively little destruction of tissue. The prognosis of primary pulmonary lymphosarcoma, like that of some other visceral lymphosarcomas, is better than that of lymphosarcoma arising in lymph nodes. The treatment has usually been surgical, as thoracotomy has been necessary to establish the diagnosis. In view of the extreme radiosensitivity of these tumours, radiotherapy might theoretically be the treatment of choice. Since this appears to be a potentially curable disease, surgical excision should be followed by radiotherapy.

We should like to record our thanks to Dr. Neville Oswald, to Dr. H. J. Partington, and to Mr. K. S. Mullard for permitting us to publish records of the patients under their care, and to Dr. T. E. W. Goodier and Dr. E. Nassau for the loan of histological sections relating to cases 2 and 3 , to $\mathrm{Mr}$. N. K. Harrison for the reproductions of radiographs, and to Mr. Peter Crocker for the photomicrographs.

\section{REFERENCES}

Azzopardi, J. G., and Menzies, T. (1960). Brit. J. Surg., 47, 358. Baron. M. G., and Whitehouse, W. M. (1961). Amer. J. Roentgenol., $85,294$.

Cooley, J. C., McDonald, J. R., and Clagett, O. T. (1956). Ann. Surg., 143, 18.

Gall, E. A. (1943). Ibid., 118, 1064.

Hall, E. R., and Blades, B. (1959). Dis. Chest, 36, 571.

Harrison, C. V. (1960). In Recent Advances in Pathology, 7th ed. p. 49, ed. C. V. Harrison. Churchill, London.

Jackson. E., Bertoli, F., and Ackerman, L. V.(1951). J. thorac. Surg. 21, 7.

Prichard, R. W., and Bradshaw, H. H. (1961). Arch. Path., 71, 420. Robbins, L. L. (1953). Cancer, 6, 80.

Rose, A. H. (1957). J. thorac. Surg., 33, 254.

Rosenberg, S. A., Diamond, H. D., Jaslowitz, B., and Craver, L. F. (1961). Medicine (Baltimore), 40, 31.

Shimkin, M. B.. Oppermann, K. C., Low-Beer, B. V. A., and Met tier, S. R. (1954). Ann. intern. Med., 40, 1095.

Sternberg, W. H., Sidransky, H., and Ochsner, S. (1959). Cancer, $12,806$.

Sugarbaker, E. D., and Craver, L. F. (1940). J. Amer. med. Ass., $115,17$.

Vieta, J. O., and Craver, L. F. (1941). Radiology, 37, 138.

Willis, R. A. (1960). Pathology of Tumours, 3rd ed., p. 772. Butterworths, London. 